\title{
A COMPARATIVE STUDY BETWEEN THE SINGLE-STAGE TRANSANAL AND SOAVE-BOLEY PULL- THROUGH FOR SHORT SEGMENT HIRSCHSPRUNG'S DISEASE
}

\author{
Md Momtazul Hoque' Md Akbar Husain Bhuiyan' Md Nur Hossain Bhuiyan ${ }^{2}$ \\ Shah Alam Talukder ${ }^{3}$ Tahmina Banu ${ }^{4}$
}

Summary

Objective:To observe the outcome between singlestage transanal and Soave-Boley pull-through operation for Hirschsprung's disease(HD) in our set up. Method: Thirty/30] patients of HD were studied from July 2006 to September 2007. Fifteen/I5] were in group-A / Transanal PullThrough (TERPT) /\& another Fifteen [15] were in group-B(Soave-Boley Pull-Through). All the patients were biopsy proven Hirschsprung's disease (HD) with barium enema suggesting lesion within recto-sigmoid region. Patients were followed-up at least for six months. Result : Age of the patients ranged from 01 months to 96 months with a mean of 31.38 months. Male female ratio was 4:1. For group-A: mean operation time was 100 mins (S.D \pm 14.76 mins), Mean length of resected aganglionic segment was $19.20 \mathrm{~cm}$. Per operative bood loss ranged from $5 \%$ to $12 \%$ of Total Blood volume (TBV) with a mean of $8 \%$. Five $(33.33 \%)$ patients needed blood transfusion. Mean hospital stay after operation was 3.73 days. Oral feeding was given wishin 24-48 hrs after having bowel sound. 01(6.66\%) patient developed enterocolitis. For group-B: mean operation time was 135 mins (S.D \pm 21.71 mins). Mean length of resected aganglionic segment was $17.40 \mathrm{~cm}$. Per operative blood loss ranged from $7 \%$ to $16 \%$ of $\mathrm{TBV}$ with a mean of $12.2 \%$. Eleven $(73.33 \%)$ patients needed blood transfusion. Mean hospital stay was 8.40 days. Three $(20 \%)$ patient developed enterocolitis after operation. Two patients (13.33\%) in Group B developed post operative intestinal obstruction among which one needed colostomy. Statistical data analysis between this two groups showed there was highly significant difference $(p<0.001)$ in the operating time, per operative blood loss and significant difference $(p<0.05)$ in blood transfusion \& post operative hospital stay between Group $A$ and Group $B$.

I. Assistant Professor of Pedistric Surgery Chittagong Medical College, Chittagong

2. Assistant Professor of Surgery

Chittagong Medical College, Chittagong

3. Professor of Surgery

Mymensing Medical College, Mymensing

4. Professor of Pediatric Surgery Chitugong Medical College, Chittagong Correspondence : Dr Md Momtazal Hoque e-mail : drmhnubel33@gmail.com.
Conclusion : This comparative study suggested that TERPT was a better procedure than SoaveBoley Pull-Through.

Key words

Soave-Boley Pull; enterocolitis; hirschsprung's disease

Introduction

HIRSCHSPRUNG'S DISEASE (HD) is a common cause of bowel obstruction in the neonatal period. The time-honored approach to therapy was to perform a preliminary colostomy in normally innervated bowel in the neonatal period and subsequent definitive pull-through procedure at a later date(at 6 to 15 months of age $)^{1}$. The surgical treatment of $\mathrm{HD}$ has evolved over the last 2 decades from traditional multistage procedures to 1-stage pull-through techniques ${ }^{2}$. Recently, the Transanal endorectal pull-through(TERPT) has gained wide popularity over open and laparoscopic assisted onestage procedures ${ }^{3}$. Compared with the traditional laparotomy such as Soave procedure, the most advantage of the transanal 1-stage pull-through operation is that it is minimally invasive and eliminates the abdominal incision resulting no abdominal scar and complications of traditional laparotomy ; the operating time and hospital delay are also cut short . Furthermore, the anal sphincter is kept in operation so that the morbidity of postoperative incontinence is sharply cut down. It has become increasingly popular to more and more doctors and patients ${ }^{4}$. But overstretching of the internal anal sphincter remains a critical issue, which may impact the long-term continence outcome $e^{5}$. however, the single-stage TERPT is relatively new in our set-up. Therefore, the study was carricd out to compare the outcome between transanal and open approach in one stage Soave-Boley pull-through operation for Hirschsprung's disease and also to present our experience with this procedure with special emphasis on its safety, feasibility and efficacy in our country.

\section{Material and methods}

This prospective comparative study from July 2006 to September 2007 was carried out in 30 Children with biopsy proven \& barium enema suggesting short segment HD. Short segment HD with associated anomalies, with hugely dilated proximal colon and operated cases with less than 6 months follow up were excluded. 
Among the 30 patients 15 were in group-A (patients underwent transanal endorectal pull-through) \& another 15 were included in group-B (patients underwent open endorectal pull-through). All the patients were followed up for at least 6 months. During the follow up period, the age at the time of operative procedure, the operating time and blood loss during operation, postoperative complications, length of follow up, functional results and parental reactions were analyzed. The data were collected in a pre designed data collection sheet and the relevant data were compiled on a master chart. The outcome variables were sub grouped. The data were analyzed using SPPS/PC program and expressed as mean $( \pm \mathrm{SD})$ or in frequency percentages. Comparison between two groups were done by Unpaired ' $t$ ' test or by $\boldsymbol{X}^{2}$ (chi-square) test as applicable. Level of significance was expressed as $\mathrm{P}$ value. $\mathrm{P}$ value < 0.05 was considered as significant and $<0.001$ was considered as highly significant.

\section{Operative technique}

The operations were performed under general anesthesia. The operation technique was followed by the combination of principles used by different investigators to obtain the

best possible results $2,3,6,7,8$. Oral feeding was given within $24-48$ hrs after having bowel sound. Digital rectal examination was done on tenth postoperative day. Routine dilatation was taught to the parents Patients were followed up on every month for the first 3 months and every three months thereafter During each follow-up, parents were asked about the stool pattern, consistency. frequency of defecation, incontinence, fecal soiling and abdominal distention. Routine general assessment was done to observe normal growth and development pattern. Digital rectal examination was routinely performed to assess the anal tone and condition of anastomotic site.

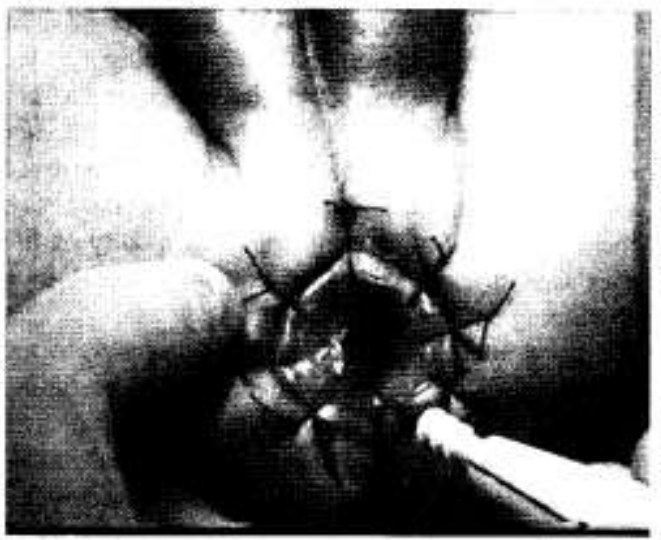

Fig 1 : Mucosal stay suture

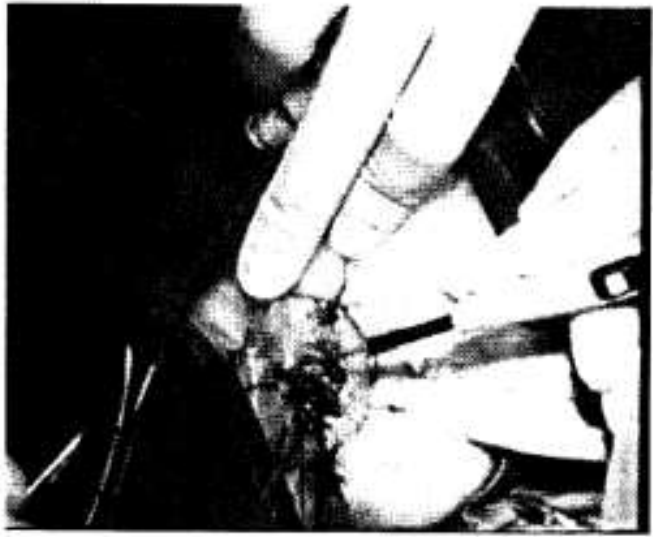

Fig 2 : Submucosal dissection

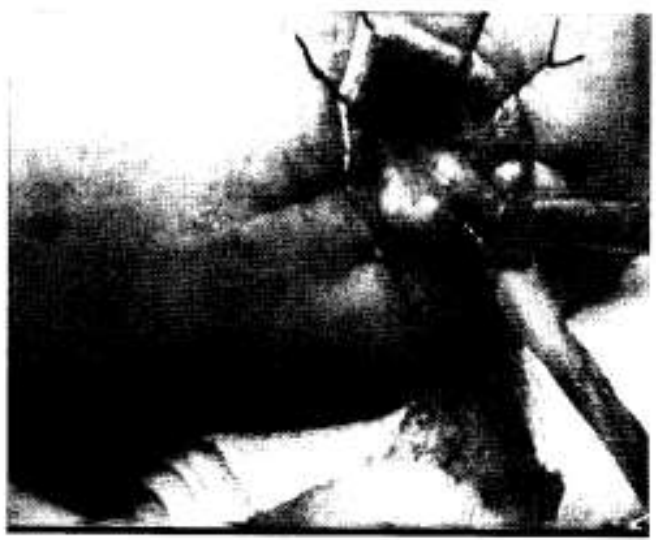

Fig 3 : Prolapsed mucosa and clinically normal looking sigmoid colon

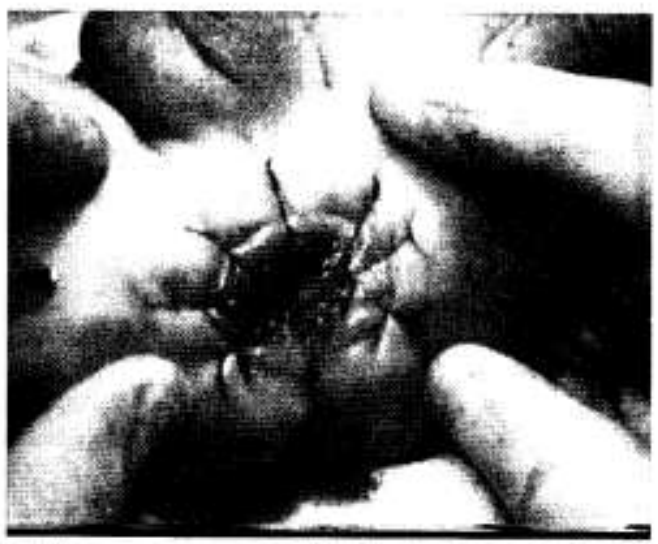

Fig 4 : Coloanal anastomosis completed 
increase in cost or operating time. So they suggested that the avoidance of the intraperitoneal laparoscopic dissection reduces the potential risk to pelvic structures and permits those surgeons who are inexperienced with advanced laparoscopic techniques to perform the operation ${ }^{12}$.

The aim of this study was to evaluate the results of TERPT in short segment HD. Special emphasis was given on the followings: duration of operation, Per operative blood loss ( $\%$ of total body weight), need for Blood transfusion, duration of post operative hospital stay, incidence of complications. These results were compared with open technique (singlestage Soave-Boley). In our scries, the average age of the patients is 27.03 months. This is much higher than the mean age of patients shown in other literature $(1-3 \mathrm{~m})^{3,12}$. This is due to low socioeconomic condition of the people and lack of appropriate referral knowledge of rural medical practitioners. The average length of resected aganglionic segment were $19.20 \mathrm{~cm}(09-28 \mathrm{~cm})$ in Group A and $17.40 \mathrm{~cm}(08-26 \mathrm{~cm})$ in Group B. Unpaired ' $\mathrm{t}$ ' test showed no significant difference ( $>>0.05$ ) in the average length of resected aganglionic segment between Group A and Group B. As the resected segment was a factor that could significantly influence the operative time, per operative blood loss and transfusion requirement; thus both the groups were matched for length of resected aganglionic segment in this comparative study. The length of resected aganglionic segment was significantly shorter than that of other study 3,12 This helped to reduce the operating time and decrease the risk of postoperative obstructive symptoms and enterocolitis, a finding also noted in some literature ${ }^{11,13}$. The average operating time in the TERPT procedure was 100 mins $(80-130$ mins). This is almost similar to study described by Hadidi ${ }^{10}$ and A. Pratap et al ${ }^{11}$. Variation in operating time was probably due to waiting for the results of the frozen section biopsies, difficult submucosal dissection due to adhesion and longer resected segment of colon \& also for lack of experiance during initial stage. The operating time is lesser than that of other study ${ }^{3,12}$. The cxact cause is not clear, but may be due to shorter resection of aganglionic segment. The average per operative blood loss was $8 \%$ of TBV $(5 \%-12 \%)$ in TERPT. It was probably due to loss of the plane of dissection in initial phase, difficult sub mucosal dissection due to adhesion in older children and longer resected segment of colon. It is our observation that sub mucosal dissection is easier, less blood loss and less time consuming in case of neonate than older children
Enterocolitis has been considered one of the main problem in patients with HD both before and after definite treatment ${ }^{11}$. In our series, enterocolitis was noted in only one patient in TERPT group (6.66\%) compared with 3 patients $(20 \%)$ in Soave-Boley group. This is compatible with study in the literature in TERPT procedure 11,14. Langer ${ }^{12}$ reported post operative enterocolitis in 4 patients (27\%) after TERPT. Leeuwen et al ${ }^{15}$ and El-Sawaf et al $^{16}$ reported a significantly higher rate of enterocolitis after TERPT. Low incidence of enterocolitis $(6.66 \%)$ in this series is probably due to short muscular cuff, rectal decompression and regular anal dilatation. The incidence of enterocolitis in Soave-Boley technique is comparable to that described by Langer ${ }^{12}$. Post operative anastomotic stenosis developed in one patient $(6.66 \%)$ in TERPT and 2 patients $(13.33 \%)$ in Soave technique. One of the patients in Open group (Soave-Boley rechnique) who developed anastomotic stenosis had anastomotic leakage previously. Another patient in Open group and one patient in TERPT group developed anastomotic stenosis due to lack of proper dilatation (failure to attend in follow-up in time). Stenosis was resolved by anastomotic dilatation under general anaesthesia for the first time and then daily home dilatation. Post operative intestinal obstruction developed in 2 patients in Open group was probably due to laparotomy, excessive handling of gut and long time exposure of bowel. Although the numbers are too small to show statistical significance, it is notable that none of the patients underwent TERPT had adhesive intestinal obstruction. Among the two patients of post operative intestinal obstruction, one patient was improved after conservative management, but another patient required immediate colostomy. In our series, parents of 29 patients $(93.66 \%)$ out of 30 patients were satisfied with the pull-through procedure, in terms of bowel pattern normalization, duration of hospital stay, absence of persistent symptomatic postoperative complication and cosmetic appearance as per their own expectation. In Open group, parents of $14(93,66 \%)$ out of 15 patients were satisfied with the outcome after Open Soave-Boley pull-through procedure. one $(6.66 \%)$ of the parents was not satisfied as her child required colostomy due to intestinal obstruction. All of the parents in TERPT group expressed their satisfaction regarding the short term outcome after TERPT; they highly appreciated the cosmetic appearance after the operative procedure as per their own expectation. 
Although the present study was carried out in a small number of patients and the follow-up period were also short in duration, this short term study suggested that TERPT was a better procedure than Open Soave-Boley Pull-Through ensuring economy by consuming significantly lesser operative time, lesser period of hospital stay, lesser amount of blood loss and lesser blood transfusion. Though there was no significantly difference between the two groups in terms of post operative complication such as post operative fever, wound infection, enterocolitis, anastomotic stenosis and post operative intestinal obstruction; TERPT was seen comparatively lesser percentages of this complication than Open SoaveBoley Pull-Through procedure in our study. Parental satisfaction without requiring any additional surgical procedure and cosmetic appearance as per their expectation was also comparatively better in TERPT. As a developing country we think that our current experience will help to established this cost effective and cosmetically accepted procedure more widely to our country as well as in other developing country.

Disclosure

All the authors declared no competing interestes.

\section{References}

1. So H.B , Becker JM, Schwartz DL and Kutin ND Eighteen years experience with neonatal Hirschsprung's Disease treated by endorectal pullthrough without colostomy. J Pediatr Surg 1998;33 ; 673-675

2. Langer J.C , Fitzgerald P.G, Winthrop A.L . Srnathan S.K, Foglia R.P, Skinner M.R, Ternberg , J.L and Lan G.Y.P. One-stage versus Two-stage Soave Pull-Through for Hirschsprung's Disease in the first year of life. J pediatr Surg 1996 ; 31:33-37

3. De la Torre Mondrago'n L. \& Ortega-Salgado JA. Transanal endorectal Pull-Through for Hirschsprung's Disease, J Pediatr Surg 1998; 33: $1283-1286$

4. Zhang S.C, Bai Y.Z, Wang W, Wang W L. Clinical Outcome in Children After Transanal 1Stage Endorectal Pull-through Operation for Hirschsprung's Disease. J pediatr Surgy 2005 ; 40 :1307-1311

5. El-sawaf M.I, Robert A.D , chamberlain J.N , coran A.G \& Teitelbaum D.H . Are the long-term results of the transanal pull-through equal to those of the transanal abdominal pull-through? A comparison of the 2 approaches for Hirschspring Disease, J pediatr Surg 2007; $42: 41-47$
6. Albanese C.T. Jennings RW, Smith B., Bratton B., \& Harrisson M.R. 1999 , "Perineal One-Stage Pull-Through for Hirschsprung's Disease, Journal of Pediatric Surgery, 1999:34:377-380

7. Boley,S.J. 1968, 'An endorectal pull through operations with primary anastomosis for Hirschsprung's Disease' , Surg , gynecol obstet . $1968 ; 127: 353-357$

8. Cass D.T, 1990 "Neonatal Surgery International One-stage Repair of Hirschsprung's Disease", Pediatric Surgery International, 1990;5:341-386

9. Kleinhaus S, Boley SJ, Sheran $M$, et al. Hirschsprung's disease: a survey of the members of the surgical section of the American Academy of Pediatrics. J Pediatr Surg 1979; 14: 588-597

10. Hadidi A,-Transanal Endorectul Pull-Through for Hirschsprung's Disease : A comparison with the open technique. Eur J Pediatr Surg 2003;13: 176 - 180

11. Pratap A, Shakya V.C, Biswas B.K., Sinha A Tiwari A , Agrawal C.S , Adhikary S. Single- stage transanal endorectul pullthrough for Hirschsprung's Disease : Perspective from a developing country. J Pediatr Surg 2007;42: 532 - 535

12. Langer J.C, Sifert M, Minkes R.K. One-stage Soave Pull-Through for Hirschsprung's Disease : A Comparison of the Transanal and Open Approaches J Pediatr Surg, $2000 ; 35 \div 820-822$

13. Rintala RJ, Transanal coloanal pull-through with a short muscular cuff ffor classic Hirschsprung's disease. Eur J Pedatr Surg 2003;13:181-186

14. Shankar K.R., Lostly P.D . Lamont G.L , Turnock R.R. Jones M.O., Lloyed D.A. Transanl Endorectal Coloanal Surgery for Hirschsprung's Disease : Experience in two centers. J Pediatr Surg2000;35: 1209-1213

15. Van Leeuwen K, Geiger i.D Barnett J.L. Coran A.G . Teitelbaum D.H .Stooling and Manometric Findings After Primary Pull-Through in Hirschsprung's Disease : Perineal Versus Abdominal Approaches. J Pediatr Surg. 2002; 37:1321-1325

16. El-sawaf M.I, Robert A.D , chamberlain J.N, coran A.G \& Teitelbaum D.H . Are the long-term results of the transanal pull-through equal to those of the transanal abdominal pull-through? A comparison of the 2 approaches for Hirschspring Disease. J Pediatr Surg. 2007; 42: 41-47 